\title{
A multi-integrated approach on toxicity effects of engineered $\mathrm{TiO}_{2}$ nanoparticles
}

\author{
Ana PICADO $(\bowtie)^{1}{ }^{1}$, Susana M. PAIXÃO $(\bowtie)^{1}$, Liliana MOITA ${ }^{1}$, Luis SILVA ${ }^{1}$, Mário S. DINIZ ${ }^{2,3}$, \\ Joana LOURENÇO ${ }^{2}$, Isabel PERES ${ }^{3}$, Luisa CASTRO ${ }^{3}$, José Brito CORREIA ${ }^{1}$, Joana PEREIRA ${ }^{4}$, \\ Isabel FERREIRA ${ }^{4}$, António Pedro Alves MATOS ${ }^{5,6}$, Pedro BARQUINHA ${ }^{4}$, Elsa MENDONCA ${ }^{1}$ \\ 1 LNEG-National Laboratory of Energy and Geology, I.P., Lisbon 1649-038, Portugal \\ 2 REQUIMTE, Chemistry Department, Fine Chemistry and Biotechnology Center, Faculty of Sciences and Technology, \\ New University of Lisbon, Caparica 2829-516, Portugal \\ 3 IMAR-Ocean Institute, Department of Sciences and Environmental Engineering, Faculty of Sciences and Technology, \\ New University of Lisbon, Caparica 2829-516, Portugal \\ 4 CENIMAT/I3N and Department of Materials Science, Faculty of Sciences and Technology, New University of Lisbon, \\ Caparica 2829-516, Portugal \\ 5 Pathological Anatomy, Curry Cabral Hospital, Lisbon 1069-166, Portugal \\ 6 CESAM, Faculty of Sciences, Lisbon University, Lisbon 1749-016, Portugal
}

(C) Higher Education Press and Springer-Verlag Berlin Heidelberg 2015

\begin{abstract}
The new properties of engineered nanoparticles drive the need for new knowledge on the safety, fate, behavior and biologic effects of these particles on organisms and ecosystems. Titanium dioxide nanoparticles have been used extensively for a wide range of applications, e.g, self-cleaning surface coatings, solar cells, water treatment agents, topical sunscreens. Within this scenario increased environmental exposure can be expected but data on the ecotoxicological evaluation of nanoparticles are still scarce. The main purpose of this work was the evaluation of effects of $\mathrm{TiO}_{2}$ nanoparticles in several organisms, covering different trophic levels, using a battery of aquatic assays. Using fish as a vertebrate model organism tissue histological and ultrastructural observations and the stress enzyme activity were also studied. $\mathrm{TiO}_{2}$ nanoparticles (Aeroxide ${ }^{\circledR}$ P25), two phase composition of anatase (65\%) and rutile $(35 \%)$ with an average particle size value of $27.6 \pm 11 \mathrm{~nm}$ were used. Results on the $\mathrm{EC}_{50}$ for the tested aquatic organisms showed toxicity for the bacteria, the algae and the crustacean, being the algae the most sensitive tested organism. The aquatic plant Lemna minor showed no effect on growth. The fish Carassius auratus showed no effect on a 21 day survival test, though at a biochemical level the cytosolic Glutathione-S-Transferase total activity, in intestines, showed a general significant decrease $(p<0.05)$ after 14 days of exposure for all tested
\end{abstract}

Received September 9, 2014; accepted January 26, 2015

E-mail: ana.picado@lneg.pt, susana.alves@lneg.pt concentrations. The presence of $\mathrm{TiO}_{2}$ nanoparticles aggregates were observed in the intestine lumen but their internalization by intestine cells could not be confirmed.

Keywords ecotoxicity, enzymatic analysis, histology, transmission electron microscopy (TEM), $\mathrm{TiO}_{2}$-nanoparticles

\section{Introduction}

Information on the properties and on potential benefits of engineered nanoparticles (ENP) and nanomaterials have been spread due to the panoply of applications from e.g. health care, to energy or environmental management, being said that nanotechnology industry is still in an exponential growth phase. The enhanced performance of the nanotech materials is the result of the unique properties of their building blocks, namely the ENP. These are manmade nanoparticles (i.e. particles with at least one of their dimensions smaller than $100 \mathrm{~nm}$ ) having properties that can differ markedly from those of their large-particle counterparts and of bulk materials [1]. The increasing penetration of materials containing ENP to the market is posing many concerns regarding their environmental impacts and health risks. In fact, predicting the risks of nanotechnology is difficult as ENP can undergo diverse physicochemical transformations that change their properties, their fate, and their impacts once released into the environment [2], but there is no doubt about the need for 